\title{
Production of Hydrogen and Carbon Black by Methane Decomposition Using DC-RF Hybrid Thermal Plasmas
}

\author{
Keun Su Kim, Jun Ho Seo, Jun Seok Nam, Won Tae Ju, and Sang Hee Hong, Member, IEEE
}

\begin{abstract}
A continuous production of carbon black and hydrogen has been investigated by thermal decomposition of methane using a prototype processing system of direct current (dc)-radio frequency (RF) hybrid thermal plasma, which has great advantage over other thermal sources like combustion or dc plasma torches in synthesizing new nanostructured materials by providing high-temperature environment and longer residence time for reactant gases due to its larger hot core region, and lower flow velocity. Appropriate operation conditions and reactor geometries for the effective synthesis process are predicted first from the relevant theoretical bases, such as thermodynamic equilibrium calculations, two-dimensional thermal flow analysis, and chemical kinetic simulation. Based on these derived operation and design parameters, a reaction chamber and a dc-RF hybrid torch are fabricated for the processing system, which is followed by methane decomposition experiments with it. The methane injected into the processing system is converted mostly into hydrogen with a small volume fraction of acetylene, and fine carbon particles of 20-50 $\mathrm{nm}$ are identified from their transmission electron microscope images. Material analyses of Brunauer-Emmett-Teller, dibutyl phthalate adsorption, and $\mathrm{X}$-ray diffraction indicate that the synthesized carbon black has excellent properties, such as large surface area, high electrical conductivity, and highly graphitized structures with good crystallization.
\end{abstract}

Index Terms-Carbon black, dc-RF hybrid plasma torch, hydrogen production, methane decomposition, numerical simulation, performance test, thermal plasma processing.

\section{INTRODUCTION}

$\mathbf{O}$ VER the past few years, several research papers have reported on the thermal plasma conversion of methane and other light hydrocarbons into hydrogen and carbon black. Especially, there has been growing interest in the production of high-grade carbon black, which has nanostructures and unique physico-chemical properties for its conductive applications, such as fuel cell, lithium ion secondary battery, and super capacitor [1]-[3]. Recently, numerous studies have been conducted on the synthesis of carbon black and/or hydrogen, mainly focused on finding new technology of their production of the best quality and purity. Among the variety of such synthesis methods, thermal plasma technology has become popular in the materials and environmental industries because of its high performance and environmentally clean process [4]-[9].

Manuscript received September 1, 2004; revised November 29, 2004.

K. S. Kim, J. S. Nam, and S. H. Hong are with the Department of Nuclear Engineering, Seoul National University, Seoul 151-742, Korea.

J. H. Seo and W. T. Ju are with Plasnix Company, Ltd., Seoul 151-742, Korea.

Digital Object Identifier 10.1109/TPS.2005.844526
Conventional processes for hydrogen and carbon black production are based on an incomplete combustion of natural gases or heavy oils, and subject to poor product yields, low price values, and high level emission of pollutants. Due to the incomplete combustion in the presence of oxygen, the furnace process is inevitably accompanied by emission of $\mathrm{CO}, \mathrm{CO}_{2}$, $\mathrm{NO}_{\mathrm{x}}$, and volatile hydrocarbons along with losses of useful hydrogen gas. In addition, the maximum reachable reaction temperature $(1500 \mathrm{~K}-2000 \mathrm{~K})$ is also limited by the amount of energy of feedstock contained [4]. Therefore, the conventional furnace process is inadequate for the production of new structured carbon black and pure hydrogen, and is unable to comply with environmental demands.

On the other hand, the thermal plasma processes with $\mathrm{dc}$ and/or RF plasma torches have turned out to be very effective and clean without emission of greenhouse gases and other pollutants in opposition to existing conventional processes. Reaction enthalpies in the process are supplied from external electrical power through arc and/or inductively-coupled discharges, and very high reaction temperature is easily achievable from 2000 up to $10000 \mathrm{~K}$, which is not obtainable by chemical reactions [10].

Fulcheri et al. developed a novel three-phase alternating current (ac) plasma process for the production of new grade carbon black and pure hydrogen [4], [7], [8]. In a series of their papers, they have shown that the thermal plasma processing has a great flexibility on controlling the synthesized carbon black properties. The dc thermal plasma process (carbon black and hydrogen process) for producing carbon black was developed and commercialized by Kvaerner Engineering Company [5], [6]. Fincke et al. also demonstrated dc thermal plasma pyrolysis of methane into hydrogen and carbon black by introducing specially designed reactor geometries for providing supersonic expansion of thermal plasma jet through a converging-diverging nozzle to increase its quenching effect on the synthesized product [9]. Furthermore, effects of operation parameters, such as temperature, pressure, and residence time of the process gases, are investigated through detailed chemical reaction simulations to optimize processing conditions and to maximize the yield of carbon products.

In this paper, a new dc-RF thermal plasma process for producing high quality carbon black and pure hydrogen is presented. A dc-RF hybrid thermal plasma torch, shown in Fig. 1, is chosen as a heat source for the decomposition of methane in this experimental work. In the dc-RF hybrid torch, very high-speed plasma jets ejected from a dc torch are expanded more broadly inside an inductively coupled RF torch energized by the additional RF power transmitted from the induction coil. In contrast 


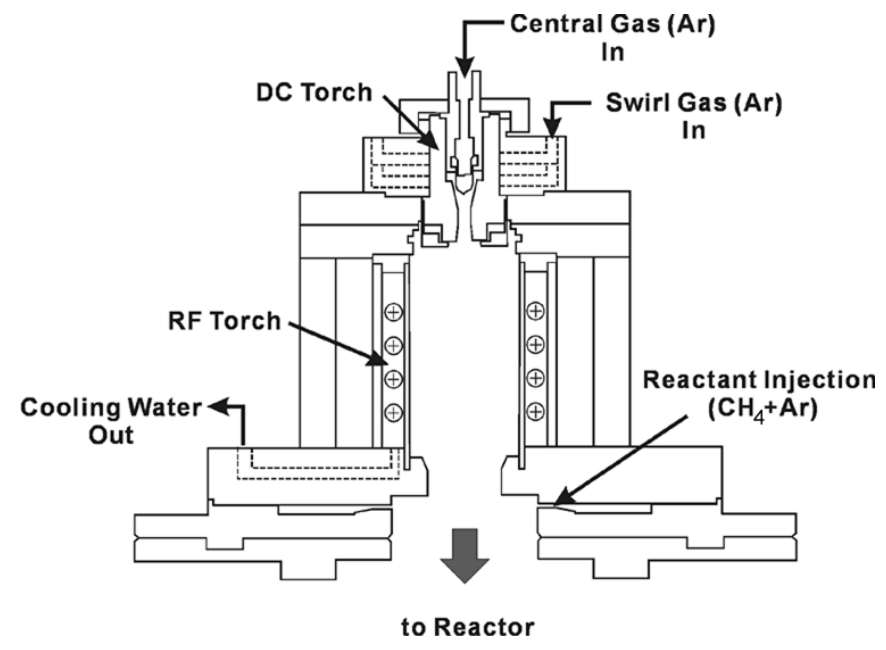

Fig. 1. Cross-sectional view of a dc-RF hybrid thermal plasma torch used for methane decomposition into hydrogen and carbon black.

to an individual de or RF plasma torch, this hybrid torch, thus, has its unique features such as lager hot thermal plasma volume, more stable jet flame, longer reaction time, no recirculation eddy in the thermal flow, ease of torch ignition, and flexibility in controlling operation parameters [11]-[14]. It is generally known that the reaction temperature and residence time play a crucial role in determining product yields and synthesis qualities like surface morphologies. In the work by Fincke et al. [9], the optimization of process was accomplished simply by increasing residence or reaction time by adopting longer reactor geometries. Fulcheri et al. have intensively investigated the relationships between reaction temperature and texture of carbon blacks [15], [16], and finally concluded that higher temperature and longer reaction time in the process results in highly developed graphitic structures at the surface of carbon particles. It is thus expected that the dc-RF hybrid thermal plasma process is very effective for generating high-quality carbon black characterized by new carbon nanostructures at the surface.

The primary goal of this experimental work is to develop a new dc-RF hybrid thermal plasma processing system for thermal decomposition of methane into carbon black and hydrogen. Prior to the actual decomposition experiments, it is needed to determine optimal reactor geometries and proper operation conditions of the process. However, up until now, little attention has been given to the thermodynamic considerations on the thermal plasma process and thermal flow characteristics inside the reaction chamber for the decomposition processing. In the first part of this paper, mixing temperatures and equilibrium compositions of a mixture of $\mathrm{CH}_{4}$ and $\mathrm{Ar}$ thermal plasma are investigated using thermodynamic data in order to find out appropriate operation conditions. Then, the temperature and velocity distributions inside the reaction chamber are computed to get its design data and to examine the heat balance over the reaction region. Lastly, zero-dimensional chemical kinetic simulations on the methane decomposition process and carbon particle formation are performed to estimate mole fractions of major reaction products by considering the detailed reaction mechanism. In the actual processing experiments based on these analytical predictions and numerical estimations, carbon black and hydrogen are produced from the suggested dc-RF

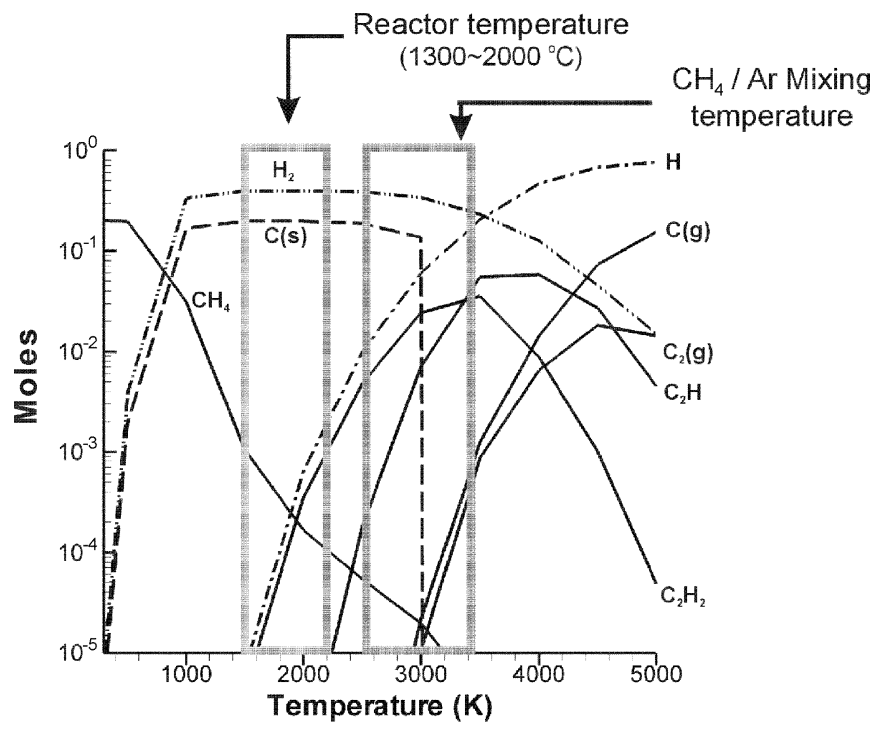

Fig. 2. Thermodynamic equilibrium compositions in a mixture of methane and argon thermal plasma with an atomic ratio of $\mathrm{C}: \mathrm{H}=0.2: 0.8$.

hybrid thermal plasma process, and physico-chemical properties of the synthesized carbon black are compared with those of other industrial reference blacks generated from furnace or existing plasma processes.

\section{THEORETICAL CONSIDERATIONS}

\section{A. Thermodynamic Calculations for Finding Operation Conditions}

The equilibrium compositions of a mixture of methane and argon plasma are calculated by the Gibbs free energy minimization method for a temperature range between 500 and $5000 \mathrm{~K}$. Although high enthalpy gases, such as $\mathrm{H}_{2}, \mathrm{~N}_{2}$ and their mixture, are commonly used in thermal plasma applications for increasing thermal energy contents, $100 \%$ argon gas is used in this work as a plasma forming gas to avoid the thermal damages on the torch material and the generation of hazardous byproducts like cyanides $(\mathrm{CN})$. The thermodynamic chemical equilibrium computation is conducted for 34 chemical species at atmospheric pressure, and the resultant equilibrium compositions for $\mathrm{CH}_{4} / \mathrm{Ar}$ plasma with an atomic ratio of $\mathrm{C}: \mathrm{H}=0.2$ : 0.8 are plotted from the discrete data calculated with an interval of $500 \mathrm{k}$ in Fig. 2. This equilibrium diagram indicates that methane decomposition takes place at above $600 \mathrm{~K}$ and completes at around $1500 \mathrm{~K}$, and thermodynamically stable products are hydrogen $\left(\mathrm{H}_{2}\right)$ and solid carbon [C(s)] appearing between $1500 \mathrm{~K} \sim 2500 \mathrm{~K}$. As the temperature increases further, hydrogen molecules are fully dissociated into hydrogen atoms, and mole fractions of $\mathrm{C}_{2} \mathrm{H}_{2}$ and $\mathrm{C}_{2} \mathrm{H}$ radicals begin to increase slowly. Thus, it is important to keep the reactor temperature above $1500 \mathrm{~K}$ to maximize the yields of hydrogen and carbon black by thorough decomposition of injected methane. If the thermally decomposed gas flow obtained at around $1500 \mathrm{~K}$ is properly quenched, further chemical reactions toward unwanted product generation and methane regeneration will be frozen, and a high conversion rate of methane to carbon black and hydrogen can be achieved. However, the actual decomposition process in the reaction chamber is not in thermodynamically equilibrium 
and chemical reaction rates are kinetically limited by the nucleation and soot growth mechanism of carbon particles. As a result, a large amount of $\mathrm{C}_{2} \mathrm{H}_{2}$ is also generated in practice, and this will be further discussed in the next section of chemical kinetic simulations.

If the mixing temperature is defined as the thermodynamic equilibrium temperature of the mixture gas obtained when a high-temperature argon plasma is perfectly mixed with an injected cold methane into the thermodynamic equilibrium state, it can be predicted from a total enthalpy curve for the mixture gas by assuming thermodynamic equilibrium state and adiabatic conditions of the process. Enthalpies are conserved in an adiabatic condition, and the initial temperatures of argon plasma and injected methane are assumed $9000 \mathrm{~K}$ and $300 \mathrm{~K}$, respectively [17]. In this work, two kinds of mixture system are considered to determine their optimal methane injection rates: mixture gas of $\mathrm{Ar}: \mathrm{CH}_{4}=1: 1$ and $\mathrm{Ar}: \mathrm{CH}_{4}=2: 1$. In the case of the mixture system for $\mathrm{Ar}: \mathrm{CH}_{4}=1: 1$, the mixing temperature turns out to be less than $1500 \mathrm{~K}$, as shown in Fig. 3(a), and is not sufficient for the thorough decomposition of injected methane, because additional thermal losses to the background caused by cooling water occur along the reaction chamber. As a result, the optimal reaction temperature is not sustainable inside the reactor and a complete decomposition of methane is not possible. On the other hand, the calculated mixing temperature for a mixture of $\mathrm{Ar}: \mathrm{CH}_{4}=2: 1$ is around $2500 \mathrm{~K}$, which is thought be sufficiently high for the complete cracking of methane. From these predicted results, it is recommended that the molar ratio of argon to methane has to be above 1.5:1 or 2:1 for the effective decomposition of methane.

By taking the above analytical results obtained from the equilibrium and enthalpy calculations as a starting point, many important process parameters for methane decomposition can be estimated including specific energy requirement (SER) for methane decomposition. From the previous consideration, it is clear that the decomposition of 1 mol of $\mathrm{CH}_{4}$ needs $1.5 \sim 2 \mathrm{~mol}$ of argon thermal plasma. Since enthalpies of $1.5 \sim 2 \mathrm{~mol}$ of $\mathrm{Ar}$ plasma at $9000 \mathrm{~K}$ are $57.68 \sim 76.90 \mathrm{~kJ}$ and the corresponding energy values are $0.079 \sim 0.105 \mathrm{kWh}$, the calculated value of average SER turns out to be about $4.9 \mathrm{kWh} / \mathrm{kg}-\mathrm{CH}_{4}$, or 2.1 $\mathrm{kWh} / \mathrm{Nm}^{3}-\mathrm{H}_{2}$, which could be further reduced by employing an additional heat recovery system and preheating of the incoming feedstock. Lowering of the mixing gas temperature can also reduce SER, however, the conversion or decomposition rate decreases as well. As a typical illustration, the operation conditions required for the hydrogen production of $10 \mathrm{Nm}^{3} / \mathrm{h}$ (and $2.5 \mathrm{~kg} / \mathrm{h}-\mathrm{CB}$ ) are found by taking advantage of the above SER data and summarized in Table I. A $60 \%$ thermal efficiency of the plasma torch is assumed in this calculation for the total required electric input power, which generally depends on operating conditions and kind of plasma gases.

\section{B. 2-D Thermal Flow Analysis Inside the Plasma Processing Reactor}

The temperature and velocity distributions inside the processing reactor are also computed to get its optimal design data and examine the heat balance over the reaction chamber. The

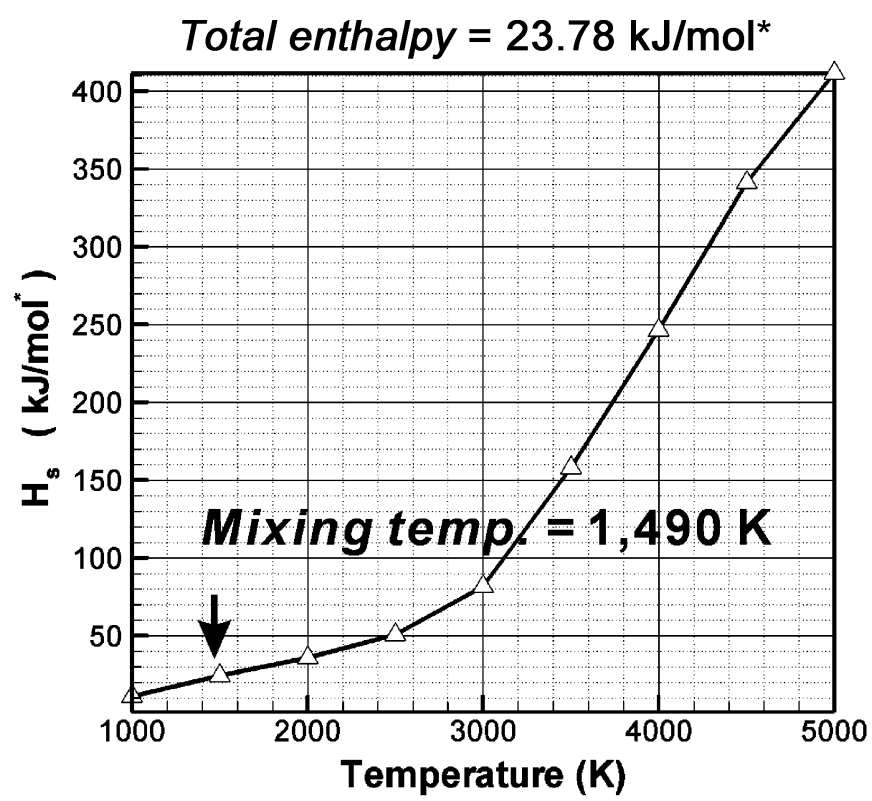

(a)

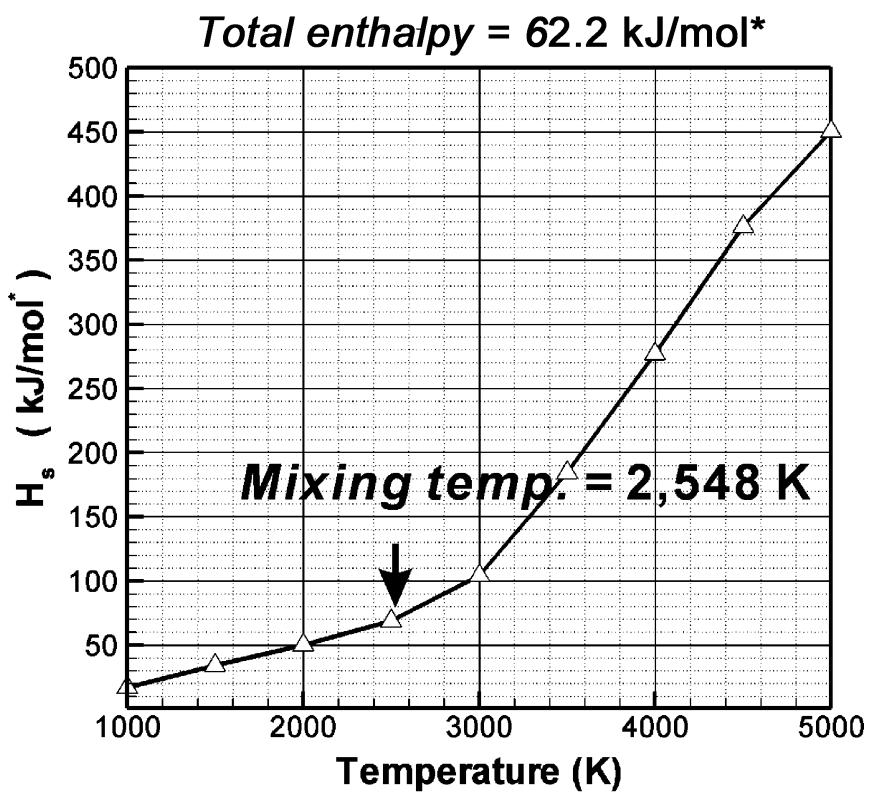

(b)

Fig. 3. Enthalpy curves depending on mixing temperature of a mixture of methane and argon thermal plasma; (a) $\mathrm{Ar}: \mathrm{CH}_{4}=1: 1$ and (b) $\mathrm{Ar}: \mathrm{CH}_{4}=$ $2: 1$.

reactor geometries considered in this computational and experimental work are depicted in Fig. 4. The reactor is designed for the hydrogen production of $10 \mathrm{Nm}^{3} / \mathrm{h}$ (and $2.5 \mathrm{~kg} / \mathrm{h}-\mathrm{CB}$ ), and a graphite liner surrounded by thermal insulator is encapsulated to control the radial gradient of processing gas temperature and minimize the thermal losses to water-cooled reactor walls. A two-dimensional (2-D) thermal flow simulation is performed by using a numerical code, FLUENT [18], without considering chemical reactions in the decomposition reactor. In other words, thorough mixing and rapid reaction between argon plasma and methane are assumed at the inlet boundary of the reaction chamber, and only their conservation equations of mass, momentum, and energy are solved in conjunction with the standard 
TABLE I

Operation Conditions Required for Hydrogen Production of $10 \mathrm{Nm}^{3} / \mathrm{h}$ (ANd $2.5 \mathrm{~kg} / \mathrm{h}-\mathrm{CB}$ ) From Thermal Plasma DeCOMPOSItion of Methane (100\% CONVERSION EFFICIENCY IS ASSUMED)

\begin{tabular}{lccccc}
$\begin{array}{l}\text { Ar/CH } \\
\text { Ratio }\end{array}$ & $\begin{array}{c}\text { Argon } \\
\text { Flow Rate }\end{array}$ & $\begin{array}{c}\text { Methane } \\
\text { Flow Rate }\end{array}$ & $\begin{array}{c}\text { Plasma } \\
\text { Power }\end{array}$ & $\begin{array}{c}\text { Total Input } \\
\text { Power }\end{array}$ & $\begin{array}{c}\text { Hydrogen } \\
\text { Production }\end{array}$ \\
\hline $2: 1$ & $167 \mathrm{slpm}$ & $83.5 \mathrm{slpm}$ & $24 \mathrm{~kW}$ & $40 \mathrm{~kW}$ & $10 \mathrm{Nm}^{3} / \mathrm{hr}^{\mathrm{b}}$ \\
\hline a Thermal efficiency of the dc -RF hybrid torch is assumed to be $60 \%$. & \\
b &
\end{tabular}

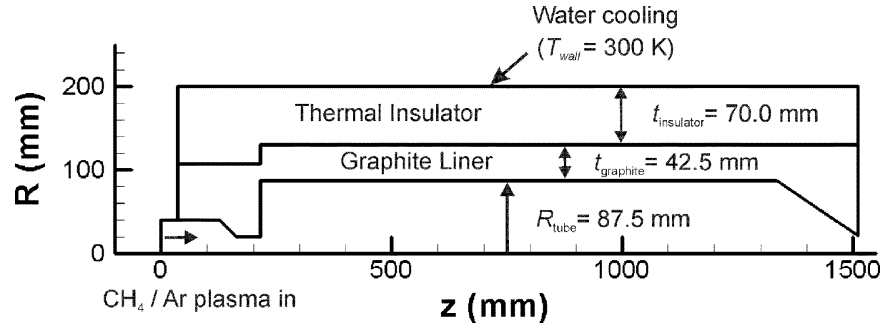

Fig. 4. Computational domain for the 2-D thermal flow analysis in a thermal plasma processing reactor.

$K-\varepsilon$ turbulent model in the interior domain of the whole chamber.

The boundary conditions at the inlet, exit, and wall are summarized for temperature, velocity, and mass fraction of species in Table II, and they are determined on the basis of the previous thermodynamic considerations and the conservation of mass flux. For example, mass fractions of chemical species $\left(\mathrm{H}_{2}=\right.$ $0.04, \mathrm{C}(\mathrm{s})=0.13)$ inside the chamber are determined from the equilibrium composition calculation by assuming reactor temperatures from 1500 to $2000 \mathrm{~K}$. The uniform profiles of temperature and velocity are simply given at the inlet boundary of computation domain, but it is expected to have little influence on the calculation results because of the long length of the reactor compared to inlet dimensions. Besides, the temperature-dependent physical and thermodynamic properties of species are used for the computation along with the transport coefficient data calculated from the kinetic theory using Lennard-Jones parameters [18].

Typically, the swirl velocity component in RF or dc-RF thermal plasmas has strong effects on the velocity and temperature fields by adding a centrifugal force to the plasma gas. In particular, the swirling flow significantly alters the original vortex-free velocity profiles, and a three-dimensional (3-D) formulation on thermal flows is essentially needed to precisely describe the trajectories of the particles and calculate their residence times. Recently, Boulos et al. [19] studied the effects of swirl on the flow and temperature fields inside and outside the RF plasma torches, and it is noted that the initial swirl velocity decays considerably fast to about $10 \%$ of its inlet value and has negligible effect on particle trajectories at the tail region of plasma flame. In this work, feedstocks are introduced into the plasma jet at $154 \mathrm{~mm}$ away from the gas inlet. According to the conclusion of Boulos et al., the swirl component is not considered in the simulations since the dc-RF hybrid plasma has stronger axial-velocity component compared to the RF plasma due to high-speed dc plasma jets superimposed on the main plasma stream. Therefore, it is reasonable that motions of particles are governed mainly by the incoming axial-velocity instead of the diminishing swirl component.

The temperature and axial-velocity profiles calculated inside the methane decomposition chamber are drawn in Fig. 5. It is clearly seen that relatively uniform radial profiles of mixing gas temperatures higher than $1500 \mathrm{~K}$ are established inside the graphite liner in the upper and intermediate stream regions reaching up to $\mathrm{z}=1.0 \mathrm{~m}$ from the reactor inlet as observed in Fig. 5(b). In general, steep gradients in radial temperature profiles and cold wall-temperature have adverse effects on the yield and quality of processed products. For instance, inhomogeneous temperature profiles produce a broad particle size distribution. By adopting a graphite liner surrounded by thermal insulator, the uniformity of processing environment is greatly improved and the high-temperature region is considerably extended toward the chamber exit. The residence time of the gas mixture along the reactor axis can be estimated from the calculated axial-velocity distribution by assuming the mixture gas as a massless entity [18], and it turns out to be greater than $0.2 \mathrm{sec}$. From the chemical kinetic simulation in the next section, it is true that the methane decomposition will take only about $5 \mathrm{~ms}$ at around $2000 \mathrm{~K}$. Thus, the residence time predicted in this simulation work is thought to be long enough for the complete decomposition of methane.

In order to examine the overall heat balance, heat losses through each component of the decomposition system are calculated. Only $21 \%$ of the heat losses take place along the reactor vessel because of the thermal insulator, and the rest of the heat is removed at the chamber end plate (39\%) and the quenching section of a heat exchanger (40\%), just after passing through the reaction chamber.

\section{Chemical Kinetic Simulation}

It is well known that the actual decomposition of methane is not an equilibrium process in the reaction chamber and usually kinetically limited. Therefore, chemical kinetic simulations under nonequilibrium conditions are needed to find out major species produced and to estimate their mole fractions for given time period and reactor geometries. In this section, a zero-dimensional chemical kinetic simulation is considered with a preassumed temperature to give a comprehensive understanding on methane decomposition process and to estimate related time scales [20].

In order to evaluate total amount of solid carbon produced, proper soot formation and growth mechanisms must be taken into account with gas phase reaction mechanism of methane 
TABLE II

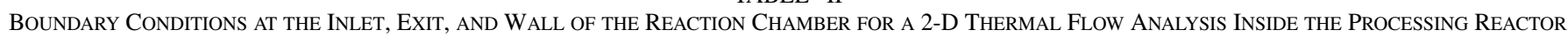

\begin{tabular}{|c|c|c|c|c|}
\hline $\begin{array}{c}\text { Mixture } \\
\text { Variables } \\
\end{array}$ & Reactor Inlet & Reactor Exit & Reactor Wall & $\begin{array}{c}\text { Graphite Liner } \\
\text { Wall } \\
\end{array}$ \\
\hline Temperature & $T=2,548 \mathrm{~K}$ & $\frac{\partial T}{\partial n}=0$ & $T=300 \mathrm{~K}$ & Calculated \\
\hline Axial-velocity & $V=52.0 \mathrm{~m} / \mathrm{sec}$ & $\frac{\partial V}{\partial n}=0$ & - & $V=0$ \\
\hline $\begin{array}{l}\text { Turbulent kinetic } \\
\text { energy }\end{array}$ & $K=0.015 V^{2}$ & $\frac{\partial K}{\partial n}=0$ & - & Wall function \\
\hline Dissipation rate & $\varepsilon=0.009 \rho K^{2} / \mu_{l}^{\mathrm{a}}$ & $\frac{\partial \varepsilon}{\partial n}=0$ & - & Wall function \\
\hline Mass fractions & $\begin{aligned} \mathrm{H}_{2} & =0.04^{\mathrm{b}} \\
\mathrm{C}(\mathrm{s}) & =0.13\end{aligned}$ & $\begin{array}{l}\mathrm{H}_{2}=0.04^{\mathrm{b}} \\
\mathrm{C}(\mathrm{s})=0.13\end{array}$ & - & $\begin{array}{l}\mathrm{H}_{2}=0.04^{\mathrm{b}} \\
\mathrm{C}(\mathrm{s})=0.13\end{array}$ \\
\hline
\end{tabular}

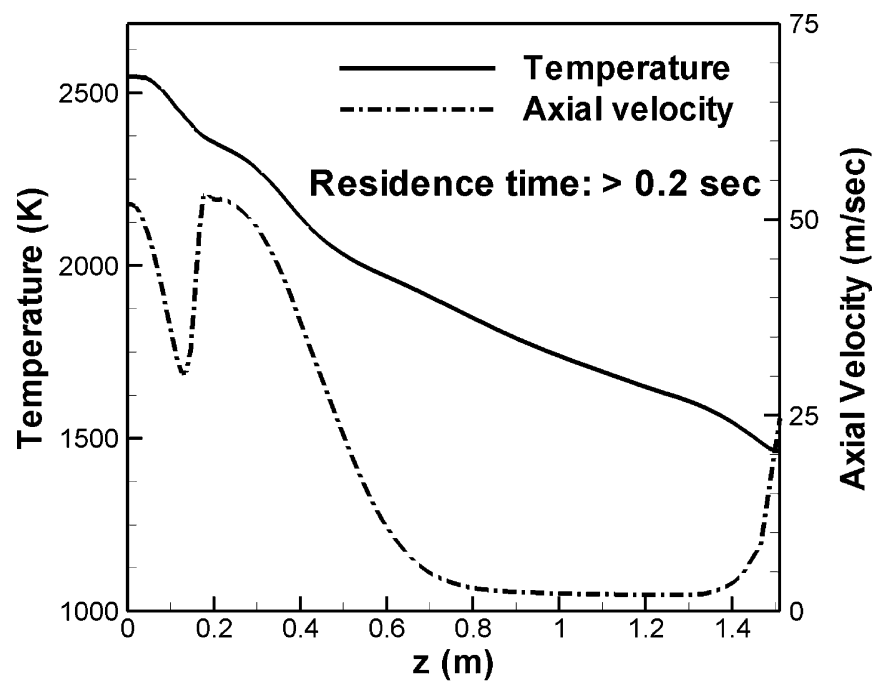

(a)

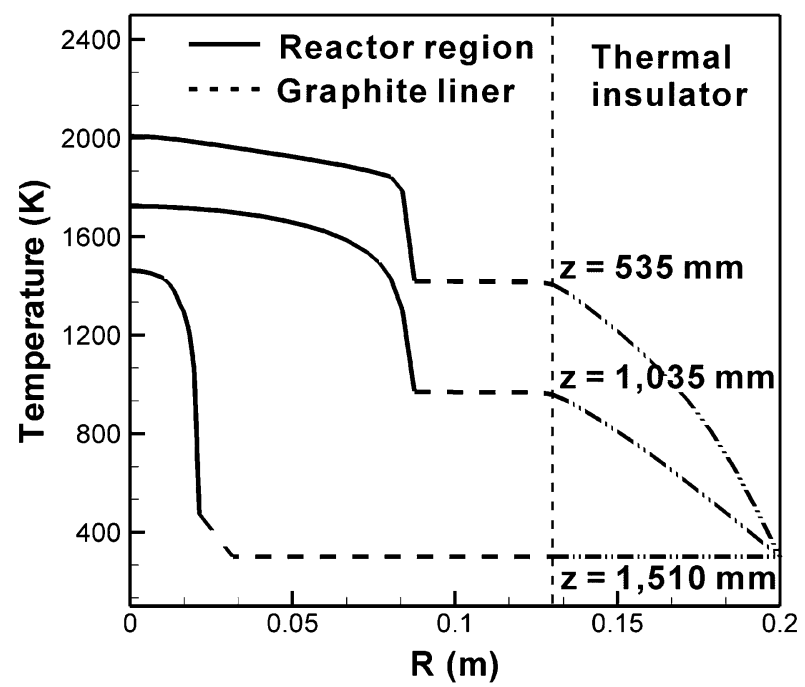

(b)

Fig. 5. Temperature and axial-velocity profiles calculated inside the reaction chamber: (a) axial profiles of temperature and axial-velocity at the reactor axis, and (b) radial profiles of temperature at $\mathrm{z}=535,1035$, and $1510 \mathrm{~mm}$. cracking. To date, several soot formation mechanisms have been proposed from many experiments on hydrocarbon pyrolysis and incomplete combustion. For example, the theories of $\mathrm{C}_{2}$ condensation, acetylene, polyacetylene, and polyaromatization are currently suggested, respectively, for the formation of carbon particulates in hydrocarbon dissociation [21]. But each theory shows shortcomings as discussed by Donnet et al. [21], and no one could correctly explain the nucleation step with generality.

Recently, Fincke et al. developed a kinetic model by employing simplified soot formation mechanism for the methane decomposition and carbon particle generation in dc thermal plasmas [9]. For the simulations of solid carbon nucleation and growth, it is assumed that primary soot particles are generated from benzene $\left(\mathrm{C}_{6} \mathrm{H}_{6}=6 \mathrm{C}_{\text {soot }}(\mathrm{s})+3 \mathrm{H}_{2}\right)$ and increase their mass continuously via the adsorption of acetylene on their surfaces $\left(\mathrm{C}_{2} \mathrm{H}_{2}+\mathrm{C}_{\text {soot }}(\mathrm{s})=\mathrm{C}_{\text {soot }}(\mathrm{s})+2 \mathrm{C}(\mathrm{s})+\mathrm{H}_{2}\right)$. In addition, detailed reaction mechanisms for PAH (polycyclic aromatic hydrocarbons) formation and carbon particle growth are avoided because of their complexities. By considering only $\mathrm{C} 1$ and $\mathrm{C} 2$, benzene formation and gas phase carbon mechanisms, Fincke et al. demonstrated that calculated results are in good agreements with experimentally measured ones. For this reason, a simplified approach is adopted in this simulation work for the convenience and for getting useful information with reasonable accuracy. This chemical kinetic model incorporated with the simplified soot formation mechanism is based on the semiempirical model of Lindstedt et al. [22] and well discussed in the Fincke et al. paper [9].

In this numerical simulation, forward reaction constants are determined by Arrhenius model, and backward ones are calculated from equilibrium constants using thermodynamic data [20]. The temperature dependent thermodynamic data are taken from the JANAF tables, and given in terms of polynomial fits for a temperature range from 300 to $5000 \mathrm{~K}$. Inert argon is also included in the calculation as an effective third body for dissociation and recombination of other chemical species. Runge-Kutta method is employed to solve a set of stiff differential equations describing chemical reactions. In this chemical kinetic simula- 
tion, 29 species and 89 chemical reaction mechanisms are considered with a complete set of their chemical reactions and corresponding rate coefficients given by Fincke et al. [9], [23] along with the following governing equations:

1) continuity equations for species

$$
\frac{\partial Y_{k}}{\partial t}=\frac{\dot{\omega}_{k} W_{k}}{\rho}
$$

2)

ideal gas law

$$
\rho=\frac{P \bar{W}}{R T}, \quad \bar{W}=\frac{1}{\frac{\sum_{k=1}^{K} Y_{k}}{\bar{W}}}
$$

3) molar production rates

$$
\begin{aligned}
\dot{\omega}_{k} & =\sum_{i=1}^{I} v_{k i} q_{i}, \quad v_{k i}=v_{k i}^{\prime \prime}-v_{k i}^{\prime}, \\
q_{i} & =k_{f_{i}} \prod_{k=1}^{K}\left[X_{k}\right]^{v_{k i}^{\prime}}-k_{r_{i}} \prod_{k=1}^{K}\left[X_{k}\right]^{v_{k i}^{\prime \prime}} .
\end{aligned}
$$

In the above equations, the subscripts $k$ and $i$ designate the $k$ th species and the $i$ th reaction, respectively. $Y$ is the mass fraction, $\dot{\omega}$ is the chemical production rate, $W$ is the molecular weight, $\rho$ is the mass density, $R$ is the universal gas constant, $T$ is the temperature, $\bar{W}$ is the mean molecular weight of a mixture, $q$ is the rate of progress, $v, v^{\prime}$ and $v^{\prime \prime}$ are, respectively, the stoichiometric coefficients of the species, reactant, and product, $k_{f}$ and $k_{r}$ are the forward and backward rate constants, and $X$ is the molar concentration.

For the decomposition simulation, the mixture system for Ar : $\mathrm{CH}_{4}=2: 1$ is considered with an assumption of thorough mixing, and initial mole fractions of argon and methane are given by 0.66 and 0.34 , respectively. During the calculations, the mixture temperature is kept constant at $2000 \mathrm{~K}$ inside the reaction chamber.

The calculated results of the zero-dimensional simulation describing the time history of methane cracking and decomposed product formation are shown in Fig. 6, in which the injected methane is immediately decomposed into elementary species and other hydrocarbons including radical and stable species. The decomposition of methane has a time scale of around $5 \mathrm{~ms}$, and the destruction efficiency (DE) of methane, defined as $\mathrm{DE}=(1-$ concentration of methane in the product stream/concentration of methane in the incoming feedstock) $\times$ $100 \%$, is found to be $99.8 \%$ from the steady state mole fraction. The relatively high fraction of methyl radical $\left(\mathrm{CH}_{3}\right)$ at the initial process stage indicates that the methyl radical plays an important role in the formation of other stable hydrocarbons, such as acetylene $\left(\mathrm{C}_{2} \mathrm{H}_{2}\right)$. Early in the conversion process, hydrogen and acetylene are observed as the major products of reaction along with a small volume fraction of solid carbon $[\mathrm{C}(\mathrm{s})]$. The formation of acetylene and hydrogen seems to be very fast and the steady state or maximum concentrations are attained during less than $1 \mathrm{~ms}$. On the other hand, the mole fraction of solid carbon particles slowly increases through the decomposition process of acetylene at their surfaces. Accordingly, a corresponding reduction in the mole fraction of acetylene is also observed after $1 \mathrm{~ms}$. At

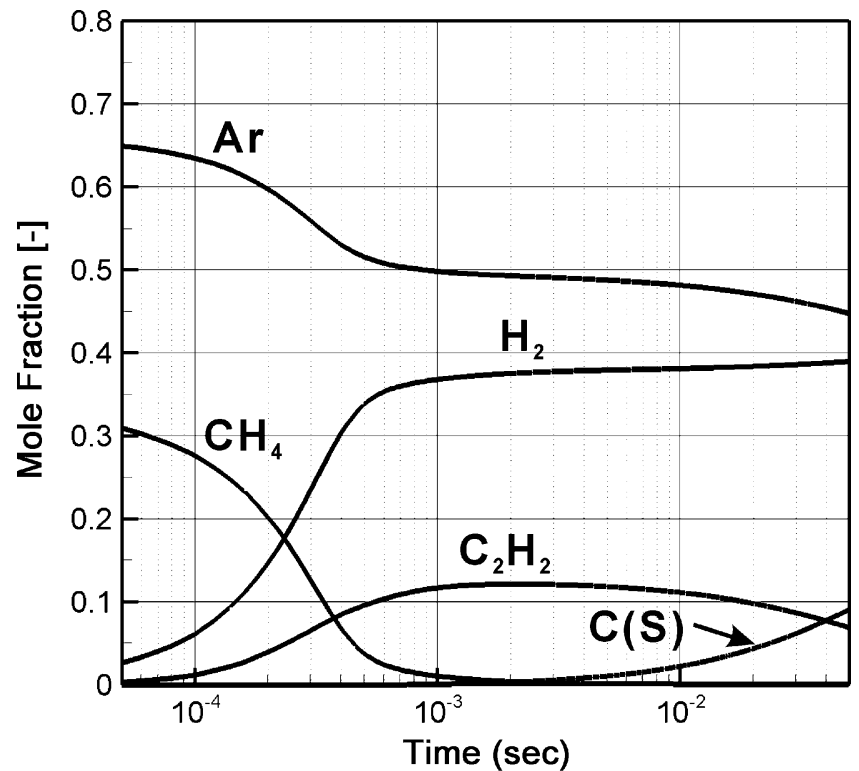

(a)

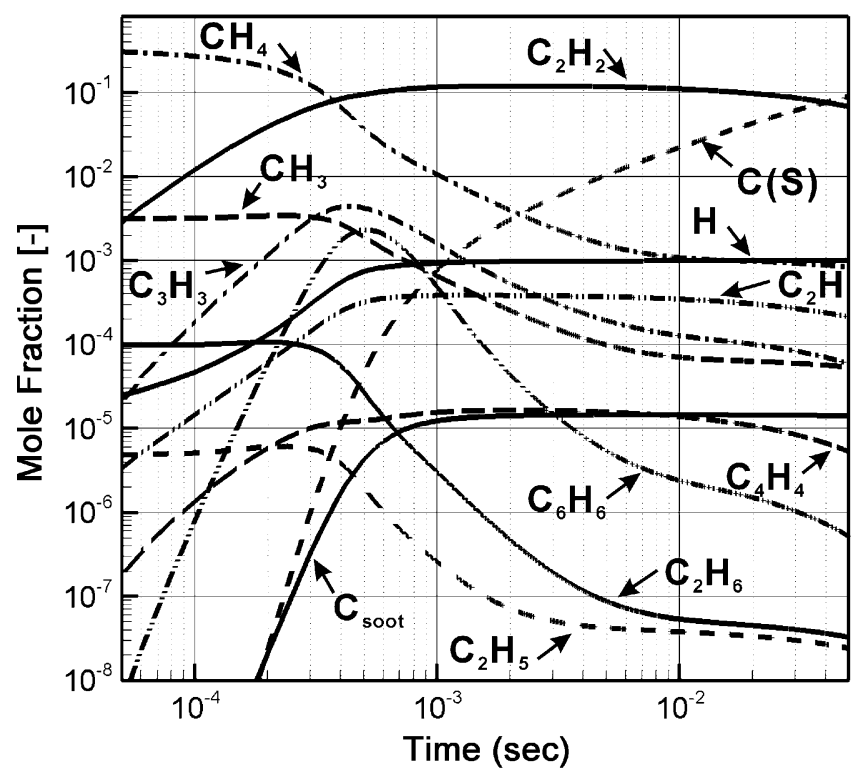

(b)

Fig. 6. Calculated mole fractions of reaction products during the $\mathrm{CH}_{4}$ decomposition by the Ar thermal plasma process: (a) main reaction products and (b) other species produced ( $\mathrm{Ar}: \mathrm{CH}_{4}=2: 1, T_{r}=2000 \mathrm{~K}$ ).

the reaction temperature of $2000 \mathrm{~K}$, the soot growth reaction $\left(\mathrm{C}_{2} \mathrm{H}_{2}+\mathrm{C}_{\text {soot }}(\mathrm{s})=\mathrm{C}_{\text {soot }}(\mathrm{s})+2 \mathrm{C}(\mathrm{s})+\mathrm{H}_{2}\right)$ seems to proceed in a forward direction, but it takes a long time to reach the equilibrium composition of the mixture because of its low reaction rate. From these results, it is expected that short reactor length or rapid cooling of the product gas stream just after reactant injection results in a high yield of acetylene instead of carbon black, because soot particles have no time to grow their mass via surface adsorption of acetylene. Consequently, it is important to provide a lengthy process time enough for the soot mass growth reaction and to keep the reactor temperature sufficiently high in order to increase growth reaction rates. After that, rapid cooling of the product gas stream with high quenching rate is needed to prevent further chemical reactions toward methane regeneration. 


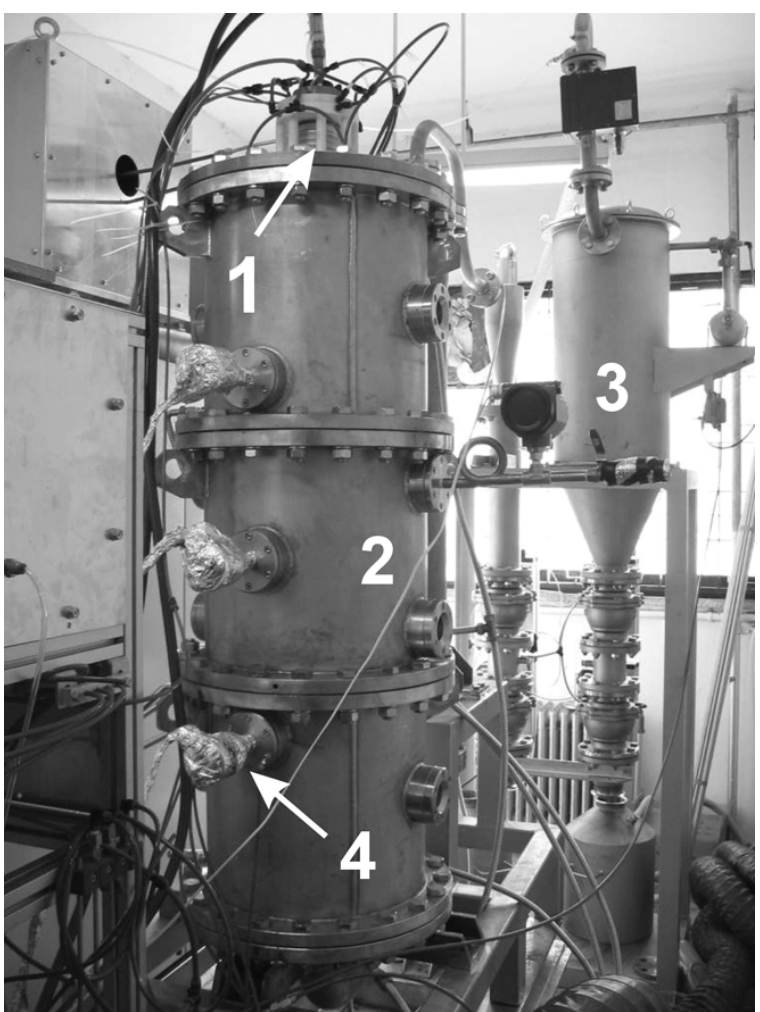

Fig. 7. Photograph of the dc-RF hybrid thermal plasma processing system for continuous production of carbon black and hydrogen by thermal decomposition of methane: (1) dc-RF hybrid torch, (2) reaction chamber, (3) solid particle separator, and (4) thermocouples.

\section{DECOMPOSITION EXPERIMENTS}

\section{A. Experimental Setup}

For the synthesis experiments for the continuous production of hydrogen and carbon black, a stainless steel reaction chamber ( $0.4 \mathrm{~m}$ in outer diameter, $1.5 \mathrm{~m}$ in length) and a dc-RF hybrid torch (a dc torch with an 8-mm anode nozzle, coupled with an $\mathrm{RF}$ torch of 50-mm-diameter confinement tube) are fabricated on the basis of the theoretical considerations [14]. Fig. 7 shows the dc-RF hybrid thermal plasma processing system developed in this work. The system is assembled with three major parts: a dc-RF hybrid torch, a reaction chamber, and a heat exchanger with particle collecting system. Injected methane is thermally decomposed into elementary species by the high-temperature thermal plasma jets inside the reaction chamber. Then, the mixture of solid particles and gaseous products are cooled down by passing through the heat exchanger, and finally separated in the cyclone and bag filter. Three thermocouples ( $\mathrm{R}$ and $\mathrm{B}$ type) are inserted into the reaction chamber for reactor temperature measurements at $\mathrm{z}=400,747$, and $1094 \mathrm{~mm}$ from the torch exit. RF power is fed by a typical 4-MHz oscillator of maximum $36 \mathrm{~kW}$, and dc power is supplied from a dc source of maximum $12 \mathrm{~kW}$.

The material properties of the produced carbon black are characterized by transmission electron microscope (TEM), $\mathrm{X}$-ray diffraction (XRD), and several static gas/oil adsorption techniques. TEM are used for investigation of surface morphologies, such as shape and size of the produced carbon particles. And structural properties of the carbon black, like inter-planar distance $\left(d_{002}\right)$, are investigated with using XRD

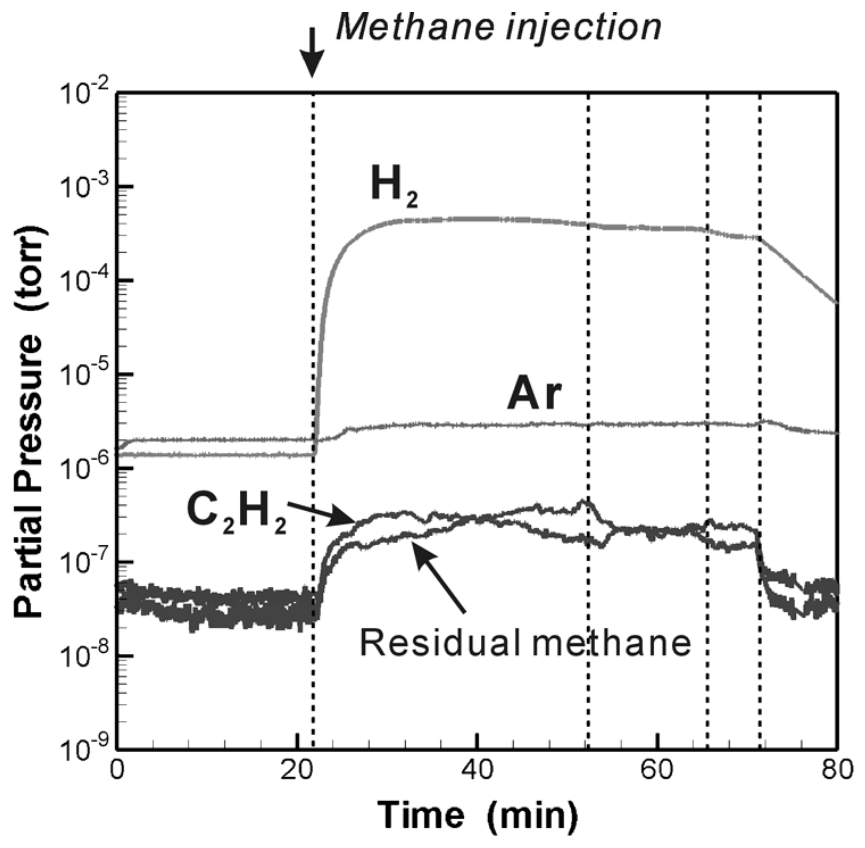

Fig. 8. Time evolution of the off-gas compositions observed by the QMS during the methane decomposition experiments. At $t=22.2 \mathrm{~min}$, methane $\left(\mathrm{CH}_{4}\right)$ is injected into the dc-RF hybrid plasma jet $(\mathrm{RF}$ power $=14.76 \mathrm{~kW}$, $\mathrm{dc}$ power $=7.60 \mathrm{~kW}, \mathrm{CH}_{4}$ flow rate $\left.=38 \mathrm{slpm}\right)$.

method. As the static gas/oil adsorption methods, BrunauerEmmett-Teller (BET) nitrogen surface area, iodine adsorption (IA) capacity, and dibutyl phthalate (DBP) adsorption capacity are measured to estimate the level of surface development [21]. Finally, electrical conductivity of the produced carbon black is measured by the van der Pauw method [24].

\section{EXPERIMENTAL RESULTS AND DISCUSSION}

\section{A. Methane Decomposition Experiments}

The methane decomposition experiments are performed with an RF power of $14.76 \mathrm{~kW}$ and a dc power of $7.60 \mathrm{~kW}$. For a stable operation of the dc-RF hybrid torch, the swirling sheath gas with a swirl ratio (axial/tangential flow rate) of 1.5 is maintained with a constant flow rate of $125 \mathrm{slpm}$ [13], [14]. The reactant $\left(\mathrm{CH}_{4}\right)$ and its carrier gas (Ar) are injected at the downstream of the plasma jet with flow rates of $38 \mathrm{slpm}$ and $35 \mathrm{slpm}$, respectively. The central gas is supplied to the RF confinement tube through the dc torch with a flow rate of $32 \mathrm{slpm}$. For these operation conditions, thermal efficiency of the hybrid torch is measured as around $65 \%$.

All decomposition experiments are conducted under an atmospheric pressure environment with the reactor preheated for $20 \mathrm{~min}$. Once the steady condition is established, feedstock of $\mathrm{CH}_{4}$ is radially injected to the hybrid plasma jet axis at the interface of the torch and the reaction chamber. Just after injection of methane, the reactor temperature rapidly drops, but recovers its original value in several tens of minutes. In the off-gas analysis, a preferential sampling of hydrogen molecules prevents the quadruple mass spectroscopy (QMS) measurement from the accurate determination of mole fractions of produced species, however, time evolutions of main gas species, such as $\mathrm{CH}_{4}$, $\mathrm{C}_{2} \mathrm{H}_{2}$, and $\mathrm{H}_{2}$, could be detected as seen in Fig. 8. A sharp rising 


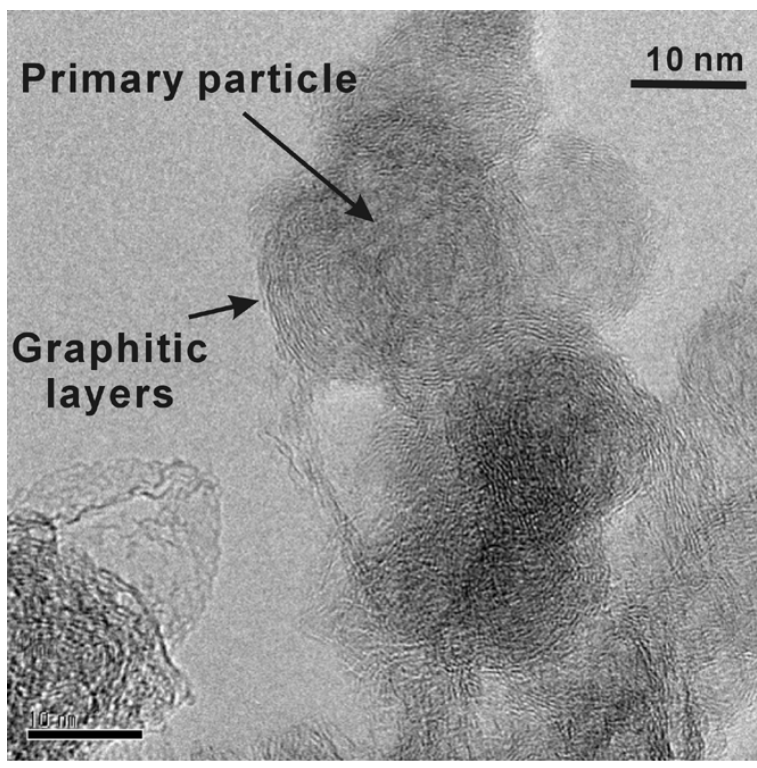

(a)

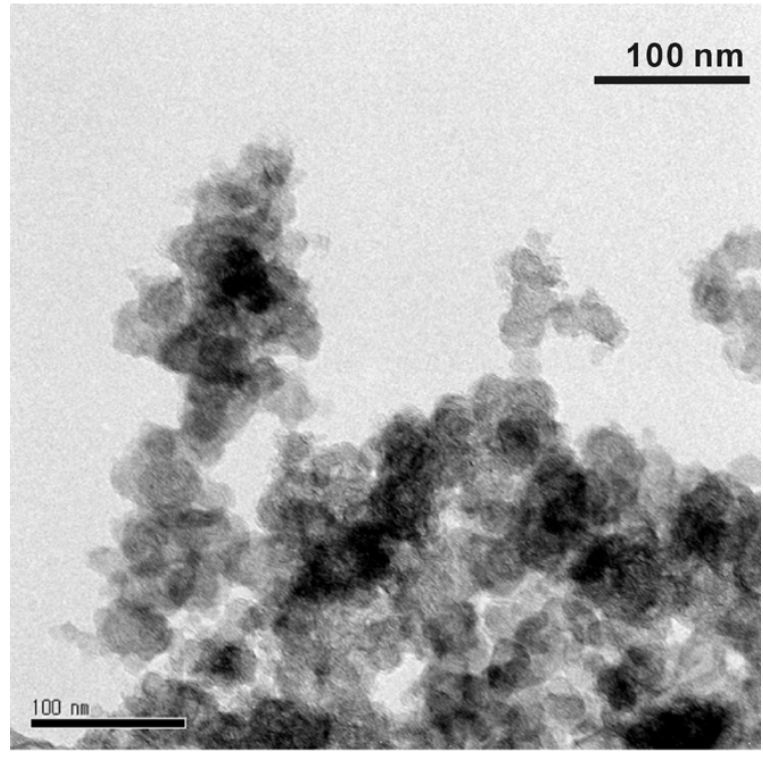

(b)

Fig. 9. TEM images of the produced carbon black: (a) high resolution image showing a turbostratic structure and (b) morphologies of carbon black aggregates.

of hydrogen concentration is observed just after methane injection, and a small volume fraction of acetylene, along with some residual methane, is measured as an evidence of methane decomposition. After approximately $1 \mathrm{~h}$ operation, a few hundred grams of carbon black are collected from the cyclone and the bag filter.

\section{B. Material Analysis on Carbon Black Properties}

The microstructure and morphological properties of the synthesized carbon black are investigated by TEM images. As clearly seen in Fig. 9(a), fine spheroidally shaped particles, whose sizes are around $20 \mathrm{~nm}$, are fused together to form a chain or cluster of carbon particles, i.e., an aggregate. In addition, graphitic layers in the individual carbon particle are certainly identified in its TEM image. This tiny particle consisting of many graphitic layers is known as a primary particle of carbon black and a basic building block of an aggregate. The graphitic layers in each particle are parallel to neighboring layers and extend in the azimuthal direction with many distortions and discontinuities. Primary carbon particles are linked to other particles by these irregular graphitic layers, and the boundary of each primary particle is not clear, as shown in Fig. 9(a).

The blurred finger printed shaped structure observed in Fig. 9(a) is known as a turbostratic structure of carbon black, and it is a semicrystalline structure which can be defined in terms of hexagonal layers stacked roughly parallel to each other with a random rotation and translation in the same plane. For this reason, many distortions and discontinuities are observed along the concentric graphitic layers in the spherical carbon particles. Moreover, this way of stacking means a two-dimensional ordering of the carbon molecules, and, consequently, graphitic layers in the particles are not parallel to the layers adjoining them and also, the spacing between the layers are not regular compared to highly organized graphite structures. At a heat treatment with temperatures in the range of 2000-3000 $\mathrm{K}$, the 2-D graphitic layers begin to align and finally form a three-dimensionally ordered graphite structure. The resultant highly graphitized carbon particle commonly exhibits a polyhedron shape instead of the spheroidal shape shown in Fig. 9(a). From the TEM image, it can be concluded that the produced carbon black is partially graphitized, i.e., turbostratic structure, but not in a complete graphite phase.

The aggregate is a basic unit of actual carbon black, and the shape and size of aggregates also have the influence on adsorption properties of carbon black. As shown in Fig. 9(b), the aggregates are well branched with many open spaces, thus it is expected that the carbon black synthesized in this work has good adsorption properties of liquid or oils. This will be confirmed by the following DBP adsorption test.

High resolution TEM images in Fig. 10 show an interesting morphology of synthesized carbon black. It looks like a thornbush as a whole [Fig. 10(a)], which consists of many thorns having wide ranges of curvatures and orientations. On the other hand, the graphitic layers inside the individual thorn are well arranged preserving a constant distance between neighboring layers with less distortions and discontinuities in contrast to the turbostratic structure [Fig. 10(b)]. From this microstructure and morphological properties, it is expected that this unique carbon black possesses a good electrical conductivity due to its high degree of crystallization, and also has a large specific surface area enhanced by the tortuous shape. The peculiar structure of the carbon black is hardly observed in conventional furnace blacks, and a systematic study on this material is needed to shed light on the formation mechanism and to characterize its physico-chemical properties.

The microstructural properties of the carbon black are further investigated using an XRD method. For the sample preparations, carbon blacks are collected from three different areas of mixing chamber, bag filter, and cyclone. The XRD pattern in Fig. 11 exhibits that most of carbon blacks collected from the mixing chamber and cyclone have highly graphitic structures due to their long exposure to the high-temperature plasma by 


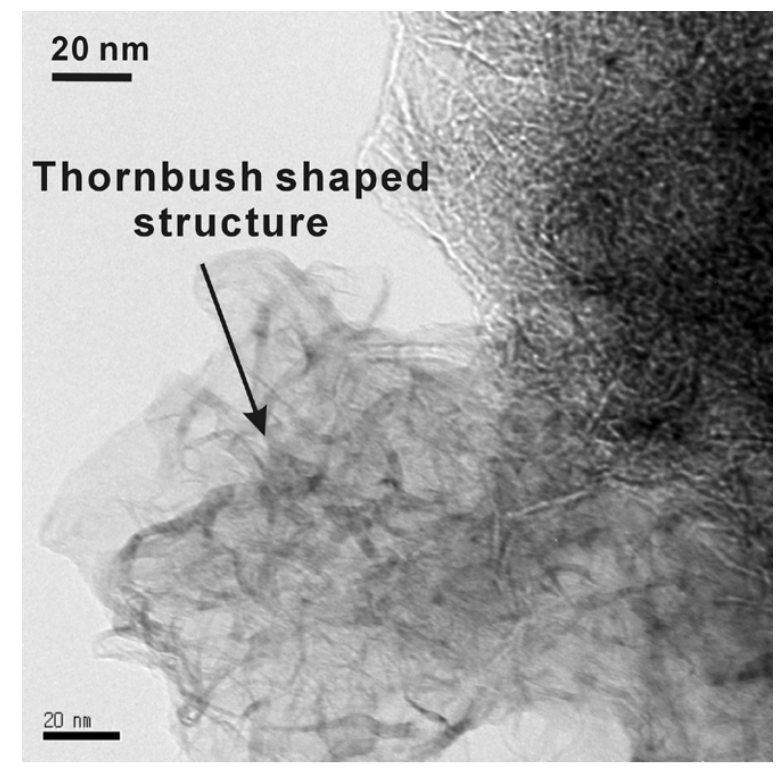

(a)

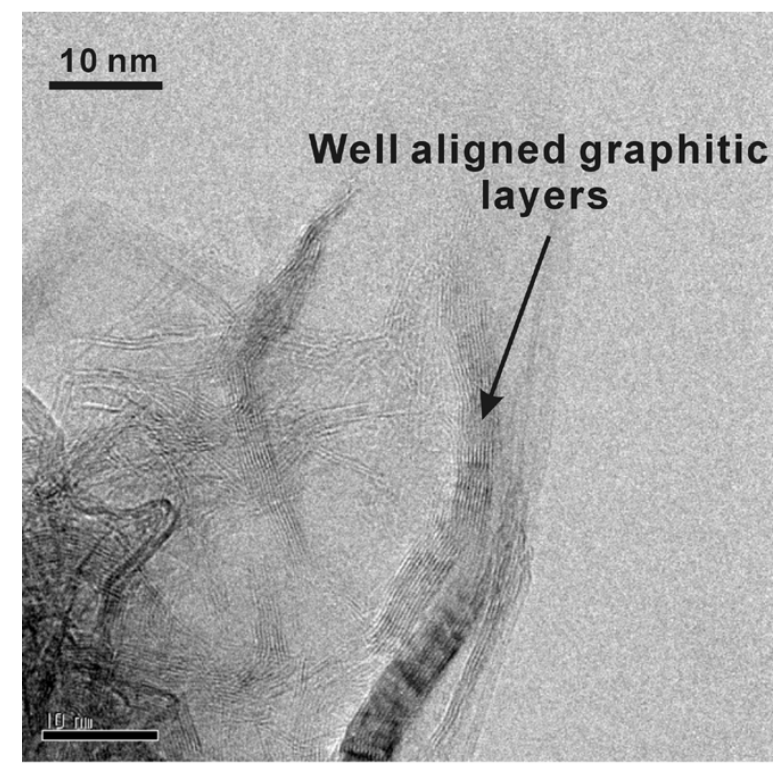

(b)

Fig. 10. TEM images of a peculiar structure appeared in the produced carbon black: (a) image of a thornbush shaped structure and (b) high-resolution image of the individual thorn.

deposition on the hot wall or by recirculation inside the reactor. On the other hand, the carbon black collected from the bag filter has a very fine size (from BET results), but a less graphitic structure. The interplanar distances of (002) planes for three carbon blacks are calculated as $d_{002}=3.45$ (mixing chamber), 3.46 (cyclone), and 3.52 (bag filter) $\AA$, respectively. Smaller interplanar distance means more densely packed particles and regular structures. As expected, the very high temperature of hybrid plasma jet and longer residence time make a great contribution to the formation of highly structured carbon particles. From both the TEM images and XRD analysis, apparently the carbon black produced by this dc-RF hybrid process is an intermediate between graphite and amorphous material close to acetylene black. A good crystallinity usually provides higher electrical conduc-

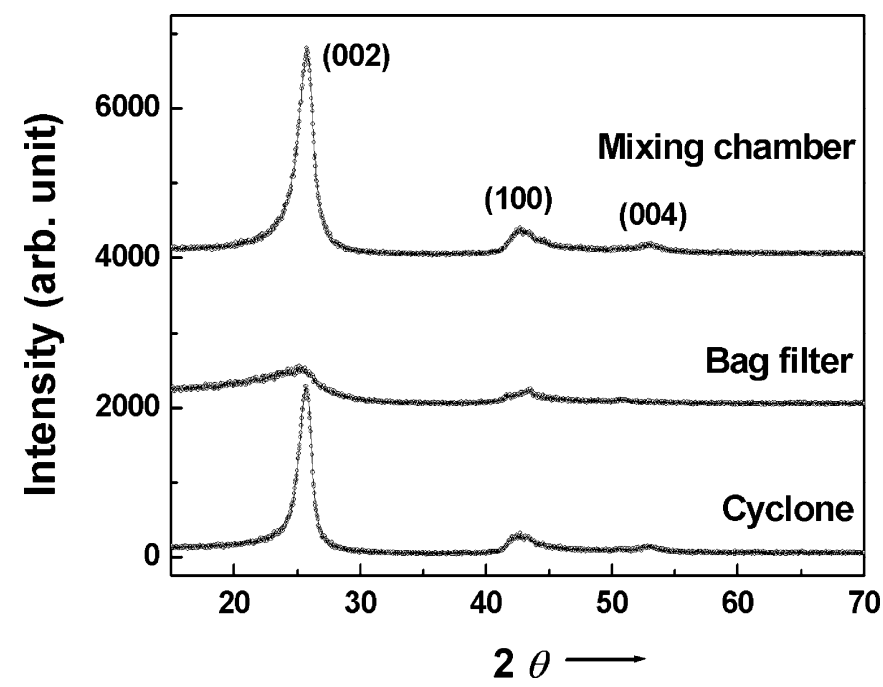

Fig. 11. X-ray diffraction patterns of the produced carbon blacks collected from three different areas of mixing chamber, bag filter, and cyclone (wavelength of $\mathrm{K}-\alpha=1.54056 \AA$ ).

tivity. Consequently, the synthesized carbon black, which exhibits a high degree of crystallization, is expected to have a great potential for conductive applications, such as electrical cell.

With the structural properties considered, the surface area is also an important property in the carbon black grade classification [21]. For determining the surface area, the standard BET with nitrogen adsorption and IA tests are employed in this work. The surface area of BET nitrogen adsorption for the produced carbon black ranges from 52.9 (cyclone) to $385 \mathrm{~m}^{2} / \mathrm{g}$ (bag filter), and the IA capacity is $119.0 \mathrm{mg} / \mathrm{g}$ (bag filter). Such high values of adsorption capacity confirm that the enhanced surface properties have been developed by this new decomposition process of dc-RF hybrid thermal plasma. In case of nonporous carbon black, surface area is inversely correlated to the primary particle size. Thus, it can be deduced that the carbon particles collected from the bag filter, which show a remarkable nitrogen adsorption capacity, have very fine sizes compared to other conventional furnace blacks. Generally, high reaction temperature reduces the primary particle size, and fine particle blacks are thus produced at higher temperature conditions. Therefore, the high-temperature process of dc-RF hybrid thermal plasma seems to be responsible for the generation of fine sized carbon black.

Since the adsorptive capacity of carbon black for liquid or oils is directly related to the shape and extent of aggregates, DBP adsorption test is now widely used for measuring the degree of aggregation in carbon black [21]. For example, aggregates with highly branched structure are capable of adsorbing more molecules of substance by generating many porous spaces in carbon black. Thus, higher adsorption values per unit weight of black represent the greater extents of the aggregate structure. DBP adsorption capacity of the carbon black synthesized in this work is measured as $149 \mathrm{ml} / 100 \mathrm{~g}$. This remarkable capacity in DBP adsorption test indicates that the structure of aggregate has been significantly developed as predicted from the previous TEM image in Fig. 9(b). 
TABLE III

Comparison of Surface Morphological Properties of CARbon BlaCKS Produced By the PRESENT dc-RF Hybrid Thermal Plasma Process With Those OBTAINed By OTHER Furnace AND CONVENTIONAL Plasma PROCESSES

\begin{tabular}{lccccc}
\hline \multicolumn{1}{c}{ Carbon Black } & IRB \#7 & N-234 & Ensaco 250 & Fulcheri $^{\text {b }}$ & Present Work \\
\hline Process & Furnace & - & M.M.M & Plasma & Plasma \\
Feedstock & PFO $^{\text {a }}$ & - & PFO & $\mathrm{CH}_{4}$ & $\mathrm{CH}_{4}$ \\
$\begin{array}{l}\text { BET (m } / \mathrm{g}) \\
\begin{array}{l}\text { DBP Ads. } \\
(\mathrm{ml} / 100 \mathrm{~g})\end{array}\end{array}$ & 80 & 125 & 65 & $65 \sim 80$ & $52 \sim 385$ \\
\hline
\end{tabular}

aPFO: Pyrolysis Fuel Oil, $\quad$ b. Fulcheri et al., Carbon, vol. 40, pp. 169-176, 2002

In Table III, the surface morphological properties of the carbon black synthesized in the present work are compared with those of other industrial reference carbon blacks, including conventional plasma blacks.

Lastly, the electrical conductivity of the carbon black synthesized by the dc-RF hybrid thermal plasma process is measured by the van der Pauw method [24]. Electrical conductivity measurements are commonly performed under compression conditions, and the measured results are significantly influenced by the compression pressure [21]. For this reason, conductivities of all carbon blacks are measured at a constant pressure of 500 $\mathrm{kgf} / \mathrm{cm}^{2}$. For comparison, the conductivity of a commercial reference black, such as Super $P$, is measured by the same method, and turns out to be $11.0 \mathrm{~S} / \mathrm{cm}$. This carbon black is currently used in lithium ion secondary battery industries as a conducting additive because of its good electrical conduction properties. The measured electrical conductivity of the carbon black produced by the present dc-RF thermal plasma process ranges from 12.0 (bag filter) to $54.0 \mathrm{~S} / \mathrm{cm}$ (cyclone) at $500 \mathrm{kgf} / \mathrm{cm}^{2}$. Normally, it is very difficult to synthesize carbon black with both high specific area and good electrical conductivity. Nevertheless, the carbon black synthesized in this dc-RF hybrid process has higher electrical conductivity compared to reference conductive black, as well as high specific area. As discussed before, a higher graphitic layer ordering generally increases the electrical conduction properties of carbon black, and thus the high electrical conductivity values are in line with the results of the previous XRD analysis.

\section{CONCLUSION}

A new dc-RF hybrid thermal plasma processing system has been developed to make an attempt to produce high-quality carbon black and pure hydrogen continuously by thermal decomposition of methane. The dc-RF hybrid plasma offers a larger volume of hot core region and lower velocity of thermal plasma flow compared with dc plasma jets. Consequently, it provides longer residence time for the reactant gas flowing along the high-temperature region with relatively uniform plasma fields across the reaction chamber. In this respect, the dc-RF hybrid plasma processing system has a great advantage over other thermal processing systems in synthesizing new materials by decomposition of hydrocarbons. For finding the effective synthesis process, optimum operation conditions, and reactor geometries are basically derived from theoretical foundations concerned with thermodynamic chemical equilibrium, thermal flow analysis, and detailed chemical kinetic simulation. Such a systematic approach developed in this work will save lots of efforts and reduce considerable time and expenses in determining operation conditions and design parameters in the course of practical thermal plasma processes.

With the design values derived from the theoretical and numerical interpretations, a dc-RF hybrid thermal plasma processing system has been fabricated, and carbon black and hydrogen are successfully generated from thermal decomposition of methane. The produced carbon black exhibits a great degree of crystallization, and seems to have a great potential for conductive applications like electrical cell. High-resolution TEM images also show a specific structure of the produced carbon black, which has not been observed in conventional furnace blacks. The carbon blacks produced in this work possess large specific surface areas and high adsorption capacities as well, and the present dc-RF hybrid plasma system turns out to be very effective for the production of carbon blacks with improved properties for their applications.

\section{REFERENCES}

[1] T. Hyeon, S. Han, Y. Sung, K. Park, and Y. Kim, "High-performance direct methanol fuel cell electrodes using solid-phase-synthesized carbon nanocoils," Angew. Chem. Int. Ed., vol. 42, pp. 4352-4356, 2003.

[2] S. Yoon, J. K. Lee, W. Cho, Y. Baek, J. B. Ju, and B. W. Cho, "An electrochemical study on the carbon black conductor prepared by plasma pyrolysis of methane" (in Korean), J. Korean Electrochem. Soc., vol. 6, pp. 6-12, 2003.

[3] T. Zielinski, T. Opalinska, and J. Kijenski. Acetylene carbon black production in plasma process. presented at Proc. 16th Int. Symp. Plasma Chem. (ISPC). [CD-ROM]

[4] L. Fulcheri, N. Probst, G. Flamant, F. Fabry, E. Grivei, and X. Bourrat, "Plasma processing: A step toward the production of new grades of carbon black," Carbon, vol. 40, pp. 169-176, 2002.

[5] S. Lynum, K. Hox, and J. Hugdahl, "Production of Carbon Black,", June 18, 1996.

[6] S. Lynum, N. Myklebust, and K. Hox, "Decomposition of Hydrocarbon to Carbon Black," U.S. Patent 6068 827, May 30, 2000.

[7] L. Fulcheri and Y. Schwob, "From methane to hydrogen, carbon black and water," Int. J. Hydrogen Energy, vol. 20, pp. 197-202, 1995.

[8] F. Fabry, G. Flamant, and L. Fulcheri, "Carbon black processing by thermal plasma. analysis of the particle formation mechanism," Chem. Eng. Sci., vol. 56, pp. 2123-2132, 2001.

[9] J. R. Fincke, R. P. Anderson, T. A. Hyde, and B. A. Detering, "Plasma pyrolysis of methane to hydrogen and carbon black," Ind. Eng. Chem. Res., vol. 41, pp. 1425-1435, 2002.

[10] E. Pfender, "Thermal plasma technology: Where do we stand and where are we going?," Plasma Chem. Plasma Process., vol. 19, pp. $1-31,1999$.

[11] T. Yoshida, T. Tani, H. Nishimura, and K. Akashi, "Characterization of a hybrid plasma and its application to a chemical synthesis," J. Appl. Phys., vol. 54, pp. 640-646, 1983. 
[12] K. Kawajiri, T. Sato, and H. Nishiyama, "Experimental analysis of a DC-RF hybrid plasma flow," Surf. Coat. Technol., vol. 171, pp. 134-139, 2002.

[13] J. H. Seo, T. H. Hwang, J. S. Nam, S. I. Choi, and S. H. Hong, "Enthalpy probe analysis on thermal plasma characteristics of DC-RF hybrid plasma jets," in Proc. 16th Int. Symp. Plasma Chem. (ISPC), Taormina, Italy, 2003.

[14] J. H. Seo, "Electrical Characteristics and Thermal Flow Dynamics of DC-RF Hybrid Thermal Plasmas," Ph.D. dissertation, Dep. Nuclear Eng., Seoul National Univ., Seoul, Korea, 2004.

[15] N. Probst, E. Grivei, F. Fabry, L. Fulcheri, G. Flamant, X. Bourrat, and A. Schroder, "Quality and performance of carbon blacks from plasma process," Rubber Chem. Technol., vol. 75, pp. 891-905, 2002.

[16] L. Fulcheri, Y. Schwob, and G. Flamant, "Comparison between new carbon nanostructures produced by plasma with industrial carbon black grades," J. Phys. III France, vol. 7, pp. 491-503, 1997.

[17] Z. G. Kostic, P. L. Stefanovic, and P. B. Pavlovic, "Comparative analysis of polychlorinated biphenyl decomposition process in air or argon (+oxygen) thermal plasma," J. Hazard. Mater, vol. 75, pp. 75-88, 2002.

[18] Fluent Inc., FLUENT 5 User's Guide, Lebanon.

[19] M. I. Boulos, R. Gagne, and R. M. Barnes, "Effect of swirl and confinement on the flow and temperature fields in an inductively coupled rf plasma," Can. J. Chem. Eng., vol. 58, pp. 367-381, 1980.

[20] R. J. Kee, F. M. Rupley, E. Meeks, and J. A. Miller, "CHEMKIN-III: A Fortran chemical kinetics package for the analysis of gas phase chemical and plasma kinetics,", Sandia Nat. Lab., Livermore, CA, Rep., SAND968216, 1996.

[21] J. B. Donnet, R. C. Bansal, and M. J. Wang, Carbon Black. New York: Marcel Dekker, 1993.

[22] K. M. Leung, R. P. Lindstedt, and W. P. Jones, "A simplified reaction mechanism for soot formation in nonpremixed flames," Combust. Flame, vol. 87, pp. 289-305, 1991.

[23] J. R. Fincke, R. P. Anderson, T. A. Hyde, B. A. Detering, R. Wright, R. L. Bewley, and W. D. Swank, "Plasma thermal conversion of methane to acetylene," Plasma Chem. Plasma Process., vol. 22, pp. 105-135, 2002.

[24] L. J. van der Pauw, "A method of measuring the resistivity and hall coefficient on lamellae of arbitrary shape," Philips Tech. Rev., vol. 20, pp. 220-224, 1958.

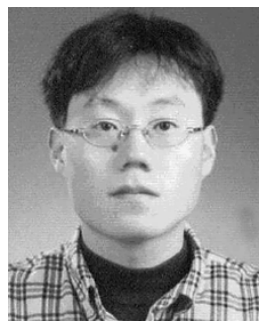

Keun Su Kim was born in Kwang Ju, Korea, in 1976. $\mathrm{He}$ received the B.S. and M.S. degrees in nuclear engineering in 1998 and 2000, respectively, from Seoul National University, Seoul, Korea, where he is currently working toward the Ph.D. degree in the Department of Nuclear Engineering.

His research interests include the plasma torch with hollow electrodes and its application to material processing and hazardous waste treatments.

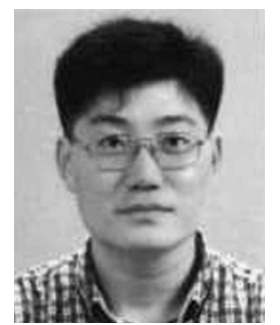

Jun Ho Seo was born in Pusan, Korea, in 1970. He received the B.S. degree in nuclear engineering and the M.S. and Ph.D. degrees from Seoul National University, Seoul, Korea, in 1994, 1996, and 2004, respectively. The topic of his Ph.D. dissertation was electrical and thermal flow characteristics of dc-RF hybrid plasma for torch design and its applications.

In February 2004, he joined Plasnix Company, Ltd., Seoul, Korea, where he is currently working on the development of dc-RF hybrid plasma torch system and thermal plasma applications. His research interests include numerical modeling and enthalpy probe measurements for dc-RF hybrid plasmas.

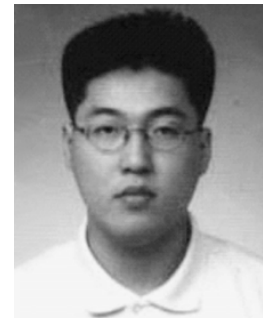

Jun Seok Nam was born in Wonju, Korea, in 1976. He received the B.S and M.S. degrees in nuclear engineering in 2002 and 2004, respectively, from Seoul National University, Seoul, Korea, where he is currently working toward the Ph.D. degree in the Department of Nuclear Engineering.

His research interests include development of dc-RF hybrid thermal plasma source and inductively coupled thermal plasma source and their applications to the material processing.

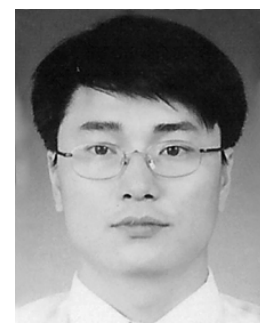

Won Tae Ju was born in Pusan, Korea, in 1968. He received the B.S. degree in nuclear engineering and the M.S. and Ph.D. degrees from Seoul National University, Seoul, Korea, in 1991, 1993, and 1998, respectively.

After completing postdoctoral training at the Thermal Plasma Technology Laboratory, Seoul National University, he joined Plasnix Company, Ltd., Seoul, as a Director. His research interests include process and system development using various type of plasma generator.

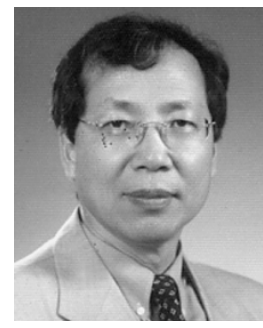

Sang Hee Hong (M'87) received the B.S. degree in applied physics from Seoul National University, Seoul, Korea, in 1974 and received the M.S. and $\mathrm{Ph} . \mathrm{D}$. degrees in electrical engineering from Colorado State University, Fort Collins, in 1975 and 1978 , respectively.

In 1979, he joined the College of Engineering, Seoul National University, where he is currently a Professor of nuclear engineering. He spent a year at the University of Sydney, Sydney, Australia, in 1989 as a Visiting Professor. His research interests in the U.S. and Australia were stability analysis of MHD flows and theory of rotating plasma and plasma centrifuges. His research interests in Korea moved to numerical modeling of tokamak plasma and industrial processing plasmas Recently, his efforts have been concentrated on tokamak plasma modeling and development of thermal plasma sources, such as dc and RF plasma torches, and pulsed corona and dielectric barrier discharge reactors, as well as their materials and environmental processing. 